\title{
Prostate-Specific Antigen (PSA) and Prostate Volume: Better Predictor of Prostate Cancer for Bosnian and Herzegovina Men
}

\author{
Jozo Coric ${ }^{1}$, Jasminka Mujic*,1, Elma Kucukalic ${ }^{2}$ and Daria Ler $^{2}$ \\ ${ }^{I}$ Department of Clinical chemistry, Clinical Center University of Sarajevo, Bosnia and Herzegovina \\ ${ }^{2}$ International University of Sarajevo, Department of Genetics and Bioengineering
}

\begin{abstract}
Background: The serum prostate specific antigen for the early detection and screening for prostate cancer are very common used among physicians as the best screening tool for prostate cancer. The result of prostate specific antigen levels discriminates whether or not a prostate biopsy should be performed. The lack of specificity is a limitation of PSA as tumor marker, increased PSA concentrations are found not only in patients with prostate cancer but also in patients with benign prostatic disease. The object of this study was to improve the specificity and sensitivity of prostatic cancer detection. We evaluated total PSA levels, free PSA levels and the prostate volume in asymptomatic patients which came for routine check without medical history of prostate cancer.

Methods: We received medical record of 90 patients between 50-60 years. Total and free PSA in serum was measured with the analyzer Architeckt i2000 SR. Prostate volume was determined by transrectal ultrasound.

Results: The ratio of total and free PSA levels to prostate volume was significantly $(\mathrm{p}<0.001)$ between all three groups. It was observed that increased prostate volume correlates with increased level of total and free PSA in serum.

Conclusion: Early studies have demonstrated the advantage of measuring prostate volume with PSA total and free levels in serum as a useful tool for early diagnosis of prostate cancer. Data from this study on 90 patients with total PSA in the range from 0,22-7,0 ng/ml confirmed the well known correlation. All three parameters total PSA, free PSA and prostate volume showed significant correlation and a useful tool in prediction of prostate cancer for Bosnia and Herzegovina men.
\end{abstract}

Keywords: Bosnia and Herzegovina, prostate volume, PSA free, PSA total, tumor marker.

\section{INTRODUCTION}

Any type of screening aims to improve early detection, decline the mortality rate and improve the quality of life. To decline the mortality rate of prostate cancer, it is mandatory to diagnose the disease at an early stage, when it is organ confined.The prostate specific antigen (PSA) assay is considered as the most useful marker for detection of prostate cancer [1,2]. The prostate cancer is one of the most common malignancies in the world and is the second leading cause of cancer mortality among Bosnian and Herzegovina men. The cancer progress very slowly and asymptomatic at the early stage, patients are unlikely to seek medical help in the early stages. Prostate marker is the only biomarker routinely used in screening and early detection even it has generated considerable debate among physicians as a screening tool. Although PSA is highly specific for prostate, an elevated level is not specific for prostate cancer; some studies have shown increased serum levels of PSA total (tPSA) in benign pathologies [3, 4]. The importance of tPSA and PSA free (fPSA) as tumor marker in evaluation of prostate cancer and also patient at risk is well reported in many studies [5-9]. Some studies have shown that screening

*Address correspondence to this author at the Department of Clinical chemistry, Clinical Center University of Sarajevo, Bosnia and Herzegovina; Tel: 00387-61-304-194; E-mail: jasminka.mujic@gmail.com for prostate cancer may have reduced prostate cancer mortality rates, but this remains controversial [15]. PSA is a serine protease produced by epithelial cells from normal and cancer prostate tissue [10]. The enzyme is not specific for prostate cancer just $20 \%$ of men with tPSA levels in serum between 4.1 and $9.9 \mathrm{ng} / \mathrm{ml}$ where reported with prostate cancer. The $\%$ fPSA, on average, lower in prostate cancer than the benign prostatic hyperplasia and has been commonly used as an aid in the diagnosis of prostate cancer. PSA testing for prostate cancer detection, however, is complicated for many reasons. Firstly, PSA exists in multiple isoforms, there are two principle forms that are current measured; PSA complex with $\alpha 1$-antichymotrypsin and uncomplexed, or fPSA. Secondly, screening with PSA is organ specific but it is not marker for cancer. Approximately $70 \%$ of men with an increased serum PSA levels, defined as $>4.0 \mathrm{ng} / \mathrm{mL}$, do not have prostate cancer [11] and this percentage undergoes unnecessary prostate biopsy. Lowering the current cutoff value $>4.0 \mathrm{ng} / \mathrm{mL}$ would detect small but clinically significant cancers. Usage of differing PSA parameters, such as age, PSA density, PSA velocity, PSA total and percentage free PSA, are still controversial tool for Prostate cancer detection [12]. There are no previous studies addressing the correlation between the range of PSA levels and prostate volume in Bosnia and Herzegovina man. The 
study was planned to evaluate the diagnostic sensitivity and specificity of percent free PSA ratio to total PSA with different prostate volume in Bosnian and Herzegovina men at age 50-60 to set better prediction opportunities for early detection of prostate cancer.

\section{METHODS AND MATERIALS}

\section{Patient Selection}

We have evaluated serum from 90 patients $(\mathrm{n}=90)$, age 50-60 for tPSA and fPSA. The patients were randomly chosen in the department of Urology in Clinical center University Sarajevo between August 2013 and September 2013. The patient with no pretreatment of prostate, no history of prostate cancer were selected. Patients suffering from urinary infection were excluded from the study. Prostate volume was determined and patients were divided into three groups, mean ratio of free-to-total PSA was calculated for each volume group.

\section{Methods}

The blood was drawn before prostate volume determination. Venous blood sample was collected in a plain tube without anticoagulant, avoiding hemolysis from each patient for total and free PSA determination. The centrifugation was done within 2-3 hours and serum was separated from the clotted blood and stored frozen at $-20{ }^{\circ} \mathrm{C}$ till analyzed. The detailed clinical history was recorded; physical examination and ultrasound findings were recorded. The time interval between sampling and performing was within 3 months. Serum total PSA and free PSA concentration were determined by a chemiluminescent microparticle immunoassay (CMIA) technology, intended for use on the analyzer Architeckt i2000 SR. Subjects were grouped according to prostate volume.

\section{Statistical Methods}

The data was compiled and analyzed in SPSS version 10.0 (SPSS, Chicago, IL, USA). The correlation of tPSA, $\%$ fPSA, and prostate volume was calculated. Student's T- test was applied as appropriate for statistical significance of the differences between the groups. $p$ value $\leq 0.05$ was considered as significant.

\section{RESULTS}

A total of 90 patients were studied age 50-60. The ratio of tPSA to prostate volume was significantly ( $\mathrm{p}<0.001)$ between all three groups (Table 1). It was observed that increased prostate volume correlates with increased level of tPSA in serum (Table 1). The fPSA was significantly lower $(\mathrm{p}<0.001)$ in patients with normal prostate volume.

\section{Correlation between Total PSA, free PSA and Prostatic Volume}

Total PSA values and other parameters such as prostatic volume, free PSA were compared (Table 1). Among the 90 patients mean total and free PSA were 0,59 to $4,05 \mathrm{ng}$. $/ \mathrm{ml}$. respectively, and free-to-total PSA ratio directly correlated with prostate volume $(\mathrm{p}=0.001)$. In tPSA ranges, the tPSA was significantly lower in the group with normal prostate volume compared to larger prostate volume and the \%fPSA values decreased with increasing tPSA concentrations

\section{DISCUSSION}

Determination of tPSA is recognized as the best diagnostic tool for the early detection of prostate cancer but studies showed the sensitivity and specificity of TPSA is not sufficient when PSA alone is used to predict the probability of prostate cancer within the $4-10 \mathrm{ng} / \mathrm{mL}$ range, approximately $75 \%$ of all biopsies will be negative. Benson and coworkers have introduced prostate volume as a useful tool to increase specificity which could show the advantage of comparing the prostate volume with prostate specific antigen serum levels. The further improvement of total PSA specificity was the measurement of free PSA and the use of $\%$ free PSA. The clinical advantage of \% free PSA, compared with total PSA, was demonstrated in the $4-10 \mathrm{ng} / \mathrm{mL}$ total PSA range [16]. Data from this study on 90 patients with total PSA, free PSA and prostate volume confirmed the well known correlation. All studies with lager cohort of patients and available data on men with total PSA in the $4-10 \mathrm{ng} / \mathrm{mL}$

Table 1. Characteristics of Patients with different Total PSA, free PSA and prostate volume.

\begin{tabular}{|c|c|c|c|}
\hline \multicolumn{5}{|c|}{ Prostate Volume Range } \\
\hline & Volume $\mathbf{4 0 \mathbf { ~ m L }}$ & Volume 40-60 $\mathbf{~ L L}$ & Volume $>\mathbf{6 0} \mathbf{~ m L}$ \\
\hline \hline Variable & & & 30 \\
\hline No. of patients & 30 & 30 & \\
\hline Total PSA (ng/mL) & & & 4,05 \\
\hline Median & 0,59 & 1,08 & $3,54-4,54$ \\
\hline Range & $0,50-0,68$ & $0,89-1,27$ & \\
\hline \% Free PSA (\%) & & & 0,55 \\
\hline Median & 0,27 & 0,33 & $0,47-0,63$ \\
\hline Range & $0,23-0,32$ & $0,25-0,40$ & \\
\hline
\end{tabular}


range demonstrated a similar performance of prostate volume and \%free PSA. Many studies have demonstrated that the free PSA/total PSA ratio (the percent free PSA [\% free PSA]) results in a significant enhancement in specificity [17]. Among patients with elevated tPSA, men with benign prostate hyperplasia tend to have higher \%free PSA ranges than men with Prostate Cancer. It would be of great interest to conduct a study on larger cohort of patients with different clinical stages.

\section{CONCLUSION}

Early studies have demonstrated the advantage of prostate volume with PSA total as a useful tool for early diagnosis of prostate cancer [13,14]. Data from this study on 90 patients with tPSA in the range from $0,22-7,0 \mathrm{ng} / \mathrm{ml}$ confirmed the well known correlation. All three parameters tPSA, fPSA and prostate volume showed significant correlation and a useful tool in prediction of prostate cancer for Bosnia and Herzegovina men. We also need to take into consideration that we have chosen a group of random patients without any clinical significance and history of prostate cancer. Moreover, a larger cohort of patients with different clinical history needs to be done to improve better prediction of prostate cancer.

\section{CONFLICT OF INTEREST}

The author confirms that this article content has no conflicts of interest.

\section{ACKNOWLEDGEMENTS}

Declared none.

\section{REFERENCES}

[1] Polascik, T.J.; Oesterling, J.E.; Partin, A.W. Prostate specific antigen: a decade of discovery - what we have learned and where we are going. J. Urol., 1999, 162, 293-306.

[2] Oesterling, J.E. Prostate- specific antigen: a critical assessment of the most useful tumor marker for adenocarcinoma of the prostate. J. Urol., 1991, 145, 907-23.

[3] Punglia, R. S.; D'Amico, A. V.; Catalona, W. J.; Roehl, K. A.; Kuntz, K. M. Impact of age, benign prostatic hyperplasia, and cancer on prostate specific antigen level. Cancer, 2006, 106(7), 1507-1513.
[4] Duffy, M.J. PSA as marker for prostate cancer: a critical review. Ann. Clin. Biochem., 1996, 33, 511-519.

[5] Labrie, F,; Dupont, A.; Suburu, R.; Cusan, L.; Tremblay, M.; Gomez, J.L.; Emond, J. Serum prostate specific antigen as prescreening test for prostate cancer. J. Urol., 1992, 147, 846-852.

[6] Brawer, M.K.; Chetner, M.P.; Beatie, J.; Buchner, D.M.; Vessella, R.L.; Lange, P.H. Screening for prostatic carcinoma with prostate specific antigen. J. Urol., 1992, 147, 841-845.

[7] Seabury, C.A.; Calenoff, E.; Ditlow, C.; Bux, S.; Clarke, H.; Issa, M.; Marshall, F.; Petros, J. Evaluation of a new serum testing method for detection of prostate cancer. J. Urol., 2002, 168, 93-99.

[8] Sawyer R, Berman JJ, Borkowski A, William MG. Elevated prostate-specific antigen levels in black men and white men. Mod. Pathol., 1996, 9, 1029-1032.

[9] Stamey, T.A.; Yang, N.; Hay, A.R.; McNeal, J.E.; Freiha, F.S.; Redwine, E. Prostate-specific antigen as a serum marker foradenocarcinoma of the prostate. N. Engl. J. Med., 1987, 317, 909-916.

[10] Catalona, W.J.; Richie, J.P.; Ahmann, F.R.; Hudson, M.A.; Scardino, P.T.; Flanigan, R.C.; deKernion, J.B.; Ratliff, T.L.; Kavoussi, L.R.; Dalkin, B.L.; et al. Comparison of digital rectal examination and serum prostate specific antigen in the early detection of prostate Cancer: results of a multicenter clinical trial of 6,630 men. J. Urol., 1994, 151, 1283-1290.

[11] Jemal, A.; Siegel, R.; Ward, E.; Murray, T.; Xu, J.; Smigal, C.; Thun, M.J. Cancer statistics, 2006. CA Cancer J. Clin., 2006, 56(2), 106-130.

[12] Auprich, M.; Augustin, H.; Budäus, L. Kluth, L.; Mannweiler, S.; Shariat SF, Fisch, M.; Graefen, M.; Pummer, K.; Chun, F.K. A comparative performance analysis of total prostate-specific antigen, percentage free prostate-specific antigen, prostate-specific antigen velocity and urinary prostate cancer gene 3 in the first, second and third repeat prostate biopsy. BJU Int., 2012, 109(11), 1627-1635.

[13] Catalona WJ, Southwick PC, Slawin KM, et al. Comparison of percent free PSA, PSA density, and age-specific PSA cutoffs for prostate cancer detection and staging. Urology, 2000, 56, 255-260.

[14] Benson, M.C.; Whang, I.S.; Pantuck, A.; Ring, K.; Kaplan, S.A.; C.A.; Cooner, W.H. Prostate specific antigen density: a means of distinguishing benign prostatic hypertrophy and prostate cancer. $J$. Urol., 1996, 147, 815-816.

[15] Hoffman, R.M. Viewpoint: limiting prostate cancer screening. Ann. Int. Med., 2006, 144, 438-440.

[16] Benson, M.C.; McMahon, D.J.; Cooner, W.H.; Olsson, C.A. An algorithm for prostate cancer detection in a patient population using prostate-specific antigen and prostate-specific antigen density. World Urol., 1993, 11, 206-213.

[17] Catalona, W.J.; Partin, A.W.; Slawin, K.M.; Brawer, M.K; Flanigan, R.C.; Patel, A.; Richie, J.P.; deKernion, J.B.; Walsh, P.C.; Scardino, P.T.; Lange, P.H.; Subong, E.N.; Parson, R.E.; Gasior, G.H.; Loveland, K.G.; Southwick, P.C. Use of the percentage of free prostate-specific antigen to enhance differentiation of prostate cancer from benign prostatic disease: a prospective multicenter clinical trial. JAMA., 1998, 279, 1542-1547.

Received: October 23, 2014
() Verma et al.; Licensee Bentham Open.

This is an open access article licensed under the terms of the Creative Commons Attribution Non-Commercial License (http://creativecommons.org/licenses/ by-nc/3.0/) which permits unrestricted, non-commercial use, distribution and reproduction in any medium, provided the work is properly cited. 